\title{
Improved design of a clothing-folding machine
}

\author{
Jie Wang, Haitian Zhang, Shujia Li
}

\begin{abstract}
With the rapid development of social life, people's requirements for quality of life are getting higher and higher. For the troubles of people sorting out clothes in daily life, and the current automatic folding machine has the disadvantages of slow working speed and high price. A folding machine is specially designed to replace people's work of clothing-folding, thereby reducing the labor process and improving the comfort of life.
\end{abstract}

Index Terms - convenient, folding machine, home, clothing

\section{INTRODUCTION}

In today's era of rapid economic and social development, people's lifestyles and attitudes to consumption have changed, and their demands for life have become higher and higher. As far as clothing, food and shelter are concerned, the number of people wearing daily clothes is greatly increased, which means that people who are modern and fast-paced and busy with life will have to spend more time on clothing storage. In addition, the indoor environment space resources are limited, and the clothes storage requirements are higher. Therefore, we invented this reel automatic folding machine, aiming to create a better tool for storing clothes to solve the above problems and troubles.

\section{BRIEF DESCRIPTION OF EXISTING FOLDING MACHINES}

In fact, in recent years, similar products have appeared in foreign countries. Panasonic's automatic folding machine relies on image processing and other functions, and it spends about 10 minutes folding a piece of clothing, which is not only time-consuming, but also costly ${ }^{[1][2]}$. The Foldimate automatic folding machine in the United States handles a piece of clothing for about 10 seconds, but it can only fold the clothes into a square shape, and there are drawbacks such as chaos and wrinkles ${ }^{[3][4]}$.

The existing machines have some problems to degrees, that is the reason that a new and convenient folding machine is designed. The machine is rolled into a cylindrical shape automatically, which can be placed in a space such as a wardrobe, a drawer, a trunk, etc, which not only saves people's time, but also saves space. And it is easy to store and take, and keeps the clothes flat and reduces the deformation of the clothes protectively.

Jie Wang, College of Mechanical Engineering, Shanghai, China, $+8618019397710$

Shujia Li, College of Mechanical Engineering, Shanghai, China, $+8618616292661$

Haitian Zhang, College of Mechanical Engineering, Shanghai, China, $+8615821988929$

Jie Wang, College of Mechanical Engineering, Shanghai, China, $+8618019397710$

Shujia Li, College of Mechanical Engineering, Shanghai, China, $+8618616292661$

Haitian Zhang, College of Mechanical Engineering, Shanghai, China, $+8615821988929$

\section{THE PRINCIPLE OF THE NEW MACHINE}

The machine is used to replace the person's manual operation to realize the folding and winding. The machine lays the clothes on the folding board, and the folding board is inclined at a certain angle. The pressure plate limits the width of the folded clothes, and the folding slider moves on the guide rail to automatically fold the clothes out of the regular rectangle. The telescopic shaft helps the garment to be formed when the garment is initially rolled. Finally, the pressure roller and the two supporting rollers cooperate to make the garment roll into a roll shape.

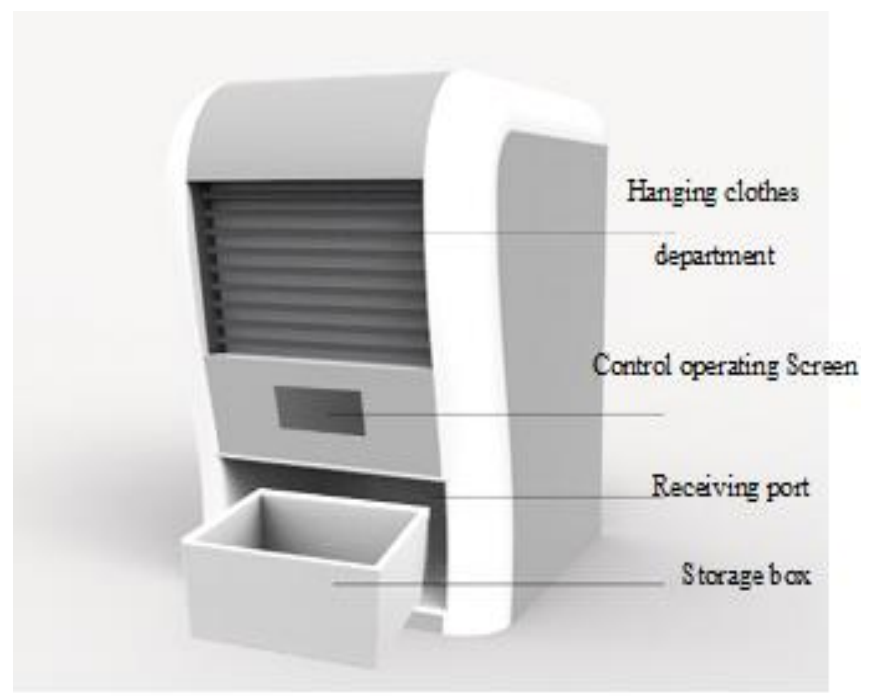

Figure 1 Folding machine

\section{A. Clothing-provided agency}

The completion of the feeding action is completed by the clothes-loading slide bar, the conveyor belt, and the clothes hook. The clothes that need to be folded are hung on the beam together with the hanger, and the two ends of the beam are connected with the belt and move together with the belt. The clothes-loading slide bar moves back and forth on the guide rail. When the clothes are sent to the bottom end of the conveyor belt, the clothes-loading slide bar also reaches the set position, and the clothes hook rotates to hook the hanger, and the clothes-loading slide bar moves in the opposite direction to send the clothes to the folding board. In particular, the bottom end of the conveyor belt is at the same height as the end point of the clothes-coating hook, and it is slightly higher than the folding board. The top end of the conveyor belt is at the same height as the top end of the guide rail, ensuring that the volume of the device is too large with the completion of the clothes-feeding function ${ }^{[5]}$ 


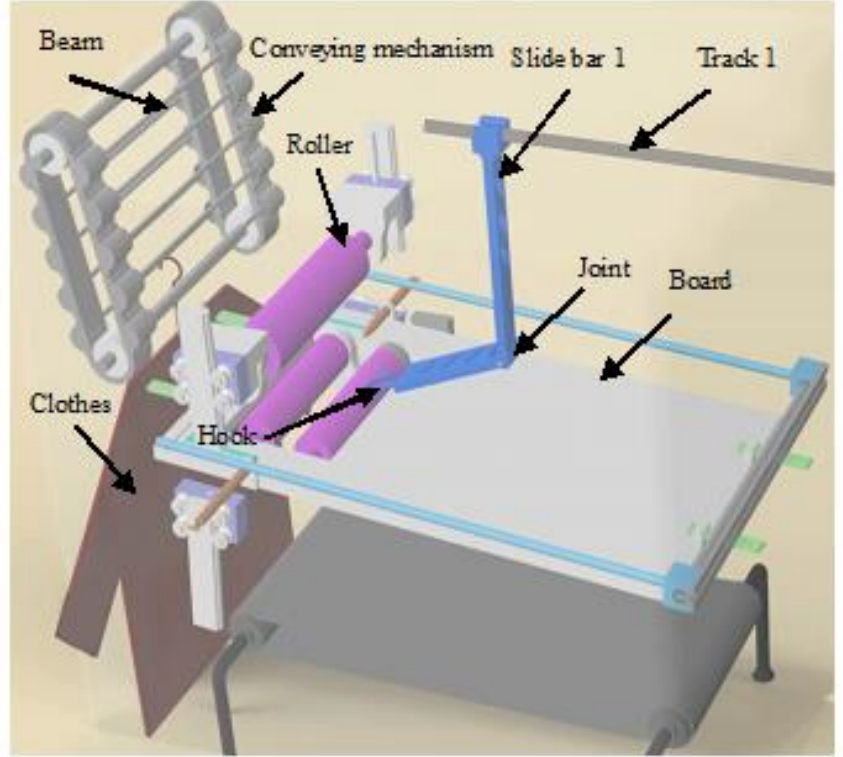

Figure2. New type of folding machine

\section{B. The process of folding}

After the clothes are delivered to the folding board, the clothes are placed on the folding slides at both ends of the folding board, and the sleeves are hung under the board. The four corners of clothes are respectively arranged with four pressure plates with a spacing of $232 \mathrm{~mm}$, pressed against the clothes, to limit the width of the folding clothes to 232 $\mathrm{mm}$. On the one hand, the pressure plate is used to control the folding width of the clothes, and to fix the clothes on the other hand. The folding slide bar is roughly the same as the clothes-loading slide bar. The clothes on the slide bar are folded inward by sliding the folding slide on the guide rails, and finally the clothes are folded into regular strips.

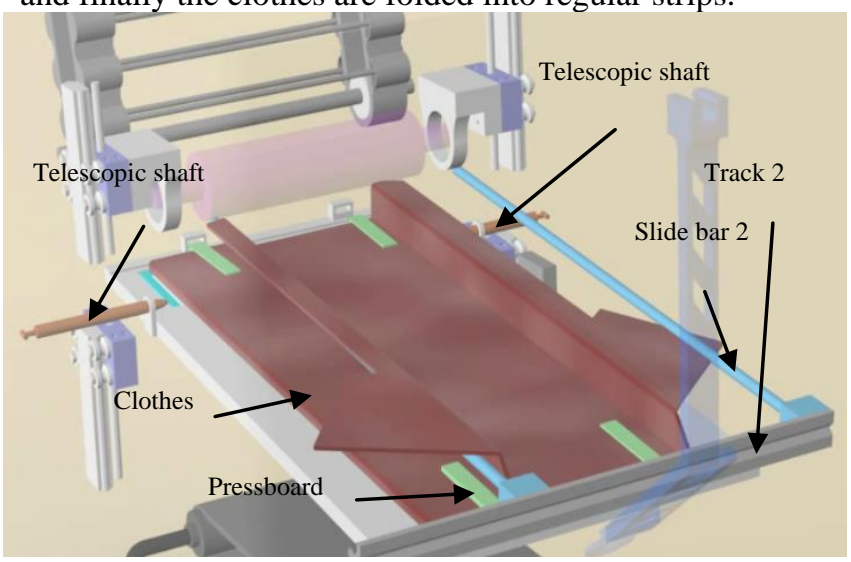

Figure3. Action of folding

\section{The process of rolling}

After the folding operation is completed, the pressure plates are returned to the position. The telescopic shaft on the left side of the folding board extends to the right by $150 \mathrm{~mm}$, the flip plate rotates $100^{\circ}$ from the initial position, and the bottom of the clothes is turned up $120 \mathrm{~mm}$. The telescopic shaft on the right side of the folding board is extended to the left by $150 \mathrm{~mm}$. The two telescopic shafts are up and down to secure the lower end of the garment. The pressure roller is moved down from the initial position by $140 \mathrm{~mm}$ to the appropriate height, and acts together with the two backup rollers under the clothes to roll the clothes into a cylinder, and the pressure roller is controlled to move down by the ball screw pair. After the clothes are formed, the two telescopic shafts are simultaneously pulled away from the clothes, and the clothes continue to roll into a cylinder of the pressure roller and backup rollers.

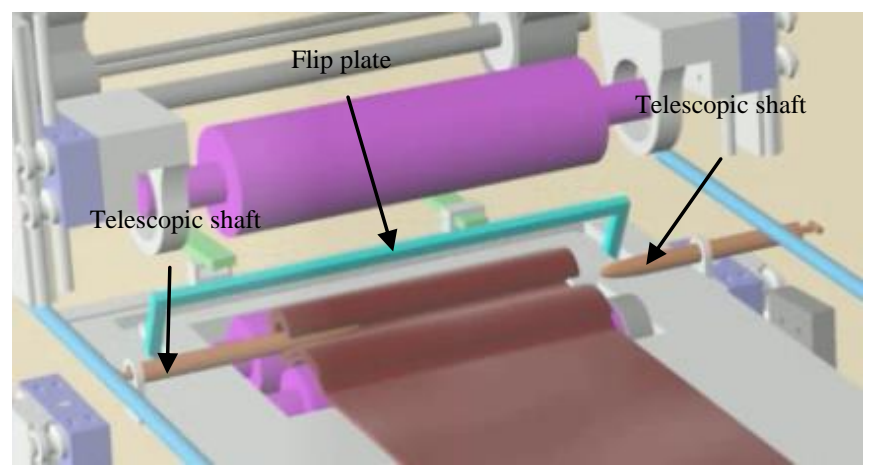

Figure4. Action of rolling

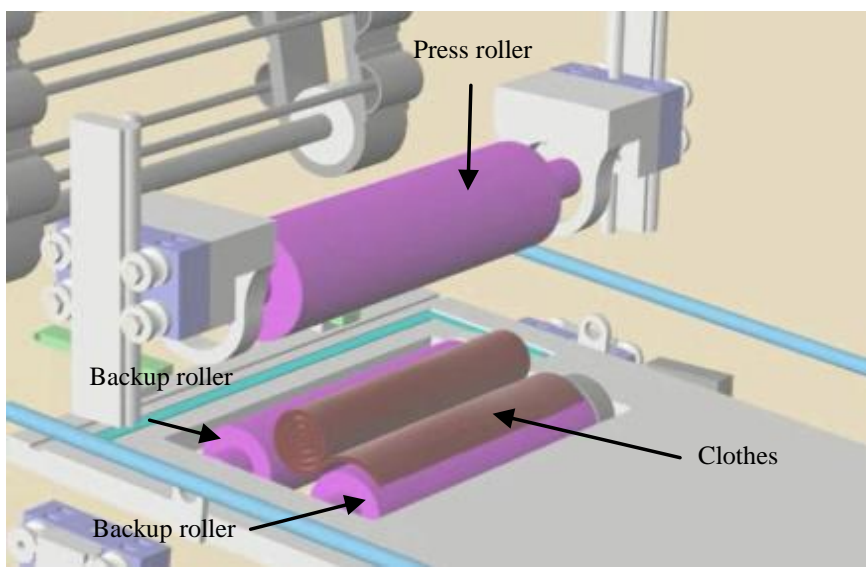

Figure5. the finish of Folding

\section{Release the finished clothes}

It illustrates the action of the garment in Figure 6. After the garment is finished, the backup rollers are reversely displaced by $140 \mathrm{~mm}$ with respect to the other roller. The formed garment is naturally dropped on the conveyor belt. And then the backup rollers reset to finish the next garment. Cylindrical clothes can keep the clothes lines well, reduce the deformation of the shoulders and the wrinkles of the clothes, and the storage effect is much better than the folding clothes.

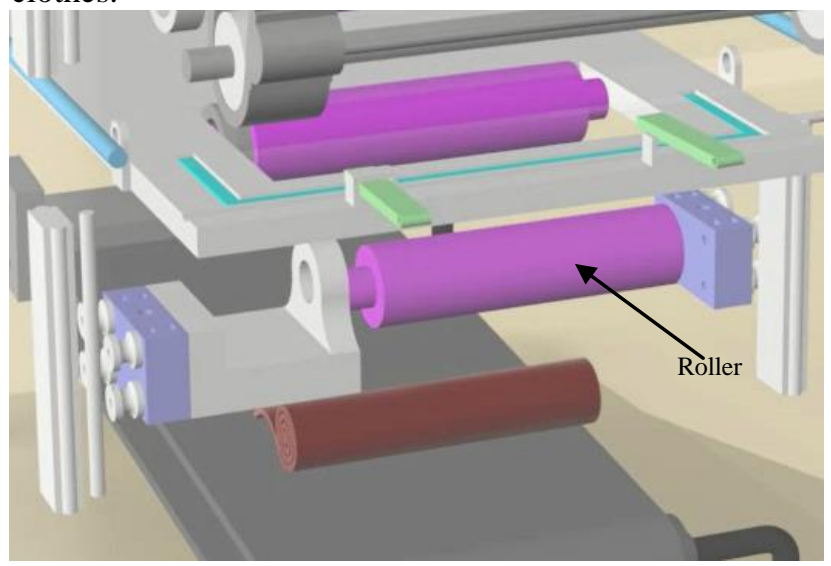

Figure6. Release the finished clothes 


\section{CONCLUSION}

Compared with the existing folding products at home and abroad, the reel automatic folding machine of this paper can roll clothes into a cylinder by mechanical automation, and the finished garments can be placed in the space of wardrobe, drawer, suitcase and the like. The design principle of the folding machine is simple, no need for high requirements such as image recognition processing, and the function is easy to implement, so that the cost is low and it is easy to popularize. The clothes processed by the device are cylindrical, have a good shape, protect the clothes lines, reduce deformation, and are easy to store. And its processing time for a piece of clothing is about 20s. In all aspects, the invention has high market value.

\section{REFERENCE}

[1] Arrange And Store Clothes. .Home Service, 2017 (01): 48-49. Available: http://kns.cnki.net/KCMS/detail/detail.aspx?dbcode=CJFQ\&dbname $=$ CJFDLAST2017\&filename $=J T F W 201701020 \& u i d=W E E v R E c w S 1$ JHSldRa1FhdkJkVG1CTXc5aEZJa1R0RUITc1BZR1Q5bjV0dz0=\$9 A4hF_YAuvQ5obgVAqNKPCYcEjKensW4IQMovwHtwkF4VYPoH bKxJw!!\&v=MzAwOTMzcVRyV00xRnJDVVJMT2ZadVJvRnl2blZ yM0FMem5OZWJHNEg5Yk1ybzlIWklSOGVYMUx1eFITN0RoMV $\mathrm{Q}=$

[2]Laundroid: The Intelligent Wardrobe for Auto-cleaning Clothes. Business Culture, 2015(30): 86. Available: http://kns.cnki.net/KCMS/detail/detail.aspx?dbcode=CJFQ\&dbname $=$ CJFDLAST2015\&filename $=$ SYWH201531022\&v=MDYzNTZWT HZNTmpUY1pyRzRIOVRQcm85SFpvUjhlWDFMdXhZUzdEaDFU M3FUcldNMUZyQ1VSTE9mWnVSb0Z5 cms=

[3]The Life Style of Lazy People. PC Digest Magazine, 2018

[4] Intelligent Wardrobe: Automatic Clothing Cleaning. Modern Group, 2015(11): 16

[5] Ge wenjie. Theory Of Machines. Beijing: Higher Education Press, 2016, pp. 14-28.

Corresponding author. \&Address:

Shujia LI, School of Mechanical Engineering. Donghua University. No.2999 North Renmin Road, Songjiang Distict, Shanghai 201620, PR China, Tel: 0086+18616292661

Jie Wang, Donghua University, Postgraduate of Mechanical Engineering.

Haitian Zhang, Donghua University, student of Mechanical Engineering.

Shujia Li, female, she is a doctor, and works as a teacher in the College of Mechanical and Engineering, Donghua University. Her research interests yarn dynamics. She is also the supervisor of a students innovation team 